Вероника Одинокова, Ксения Ерииян, Майя Русакова, Нина Усачева

\title{
ФАКТОРЫ ВОВЛЕЧЕНИЯ В ПРОСТИТУЦИЮ В НЕСОВЕРШЕННОЛЕТНЕМ ВОЗРАСТЕ: РЕЗУЛЬТАТЫ ЭМПИРИЧЕСКОГО ИССЛЕДОВАНИЯ ВЗРОСЛЫХ ЖЕНЩИН
}

\begin{abstract}
Проституция рассматривается исследователями с позиций одной из основных парадигм: как девиация, как секс-работа или как насилие. Однако если речь идет о несовершеннолетних, то международные нормативные документы однозначно трактуют проституцию как форму сексуальной эксплуатации. На материалах эмпирического исследования взрослых женщин, занимающихся проституцией в Санкт-Петербурге и Оренбурге $(\mathrm{N}=654)$, мы изучили обстоятельства начала занятия проституцией в зависимости от возраста начала - до 18 лет или старше. В исследование были включены взрослые женщины, занимающиеся проституцией на улицах, в гостиницах, салонах, на вокзалах и индивидуально. Влияние различных факторов на начало занятия проституцией в возрасте до 18 лет оценивалось с помощью критерия согласия $\chi^{2}$ Пирсона и бинарного логистического регрессионного анализа. Каждая десятая женщина в выборке начала заниматься проституцией до наступления совершеннолетия. Первый опыт оказания сексуальных услуг за деньги респонденты, независимо от возраста начала занятия проституцией, в половине случаев оценивают как недобровольный (из-за уговоров, давления или применения силы). Основными факторами вовлечения в проституцию в возрасте до 18 лет являются семейное неблагополучие, ранний возраст пробы
\end{abstract}

Вероника Александровна Одинокова - к.с. н., ст. н.с., Социологический институт ФНИСЦ РАН, Санкт-Петербург, Россия. Электронная почта: veronika.odinokova@gmail.com

Ксения Юрьевна Ерицян - к. п. н., старший преподаватель, Национальный исследовательский университет «Высшая школа экономики», Санкт-Петербург, Россия. Электронная почта: ksenia.eritsyan@gmail.com

Майя Михайловна Русакова - к.с.н., ст. н.с., Социологический институт ФНИСЦ РАН, Санкт-Петербург, Россия. Электронная почта: maia@ngostellit.ru

Нина Михайловна Усачева - мл. н. с., Социологический институт ФНИСЦ РАН, СанктПетербург, Россия. Электронная почта: marudova_n.m@mail.ru 
наркотиков и др. Мы заключаем, что группа женщин, занимающихся проституцией, неоднородна. Жизненные траектории, приводящие в проституцию детей и взрослых, могут существенно различаться. Жесткая теоретическая позиция, основанная на обобщении всех женщин, занимающихся проституцией, как жертв, «девиантов» или работниц, неминуемо игнорирует потребности и интересы части из них. В современной российской социальной политике проституция рассматривается как девиация, которая запрещена и влечет за собой административную ответственность. Общественно-политические дискуссии о мерах контроля проституции включают в себя обсуждение как легализации, так и ужесточения контроля и наказания за проституцию, однако вопросы профилактики вовлечения, а также помощи на этапе «выхода» из проституции незаслуженно исключены из этой дискуссии.

Ключевые слова: проституция, сексуальная эксплуатация, насилие, несовершеннолетние, секс-работа

DOI: 10.17323/727-0634-2019-17-2-267-280

Конвенция ООН о правах ребенка (1989) привлекла внимание большинства стран к необходимости защиты детей. Вовлечение несовершеннолетних в проституцию признано сексуальной эксплуатацией детей - СЭД (ООН 2000). Понимание проституции несовершеннолетних как насилия, основанного на уязвимости, незрелости и подчиненном положении ребенка, разделяют многие исследователи этой проблемы (напр., O'Connell, Davidson 2005). Не так однозначно обстоят дела со взрослой проституцией. В науке и социальной политике доминируют несколько различных объяснений проституции, в том числе: как девиации, как вида трудовой занятости, как насилия и эксплуатации (см.: Гилинский 2004; Нартова, Крупец 2010; Русакова 2010). Многие исследователи априори исходят из той или иной теоретической ориентации в вопросе изучения проституции и подчиняют ей свои выводы. Распространено рассмотрение женщин, занимающихся проституцией, как преимущественно совершеннолетних. При этом исследователи взрослой проституции и СЭД действуют независимо и игнорируют возможность их преемственности.

Ряд зарубежных исследователей ставит под сомнение правомерность разделения проституции на «сексуальную эксплуатацию детей» и «взрослую проституцию» (Marcus et al. 2012). Превращается ли «насилие» в «секс-работу» автоматически по достижении 18 лет? Насколько обоснованно разделение взрослой проституции и СЭД? Для ответа на этот вопрос требуется более детальное изучение факторов и условий вовлечения в проституцию и возможностей «выхода» из нее в зависимости от возраста начала занятия проституцией. Цель нашего исследования - на материале собственного социологического опроса взрослых женщин, занимающихся проституцией, охарактеризовать специфику социальных 
факторов и обстоятельств, характерных для начала занятия проституцией до достижения совершеннолетия.

Сравнительных эмпирических исследований вовлечения в проституцию в раннем или позднем возрасте очень мало, и результаты их не всегда согласуются. Количественные исследования, проведенные в США и Мексике, показывают, что раннее начало занятия проституцией положительно связано с потреблением наркотических субстанций и рядом других факторов (Clarke et al. 2012; Loza et al. 2010). При этом в мексиканской выборке значимым фактором также оказалось пережитое в детстве жестокое обращение, а в американской такая связь не была обнаружена. В недавнем исследовании этой проблематики, проведенном в США с использованием качественной методологии (Cobbina, Oselin 2011), авторы показали, что взрослые женщины начинали заниматься проституцией либо в результате наркотической зависимости, либо в результате нужды. У несовершеннолетних обнаружены два иных пути вовлечения в проституцию: вследствие жестокого обращения, в том числе физического и сексуального насилия, вынудившего их к уходу из дома, либо вследствие воспитания в среде, где проституция была распространена и нормализована. В России до настоящего времени подобных исследований не проводилось.

\section{Методы}

Выборку исследования составили женщины, оказывающие сексуальные услуги за вознаграждение в двух российских городах (СанктПетербурге и Оренбурге) в различных условиях: на улицах, в гостиницах, в «салонах», на вокзалах и индивидуально $(\mathrm{N}=896)$. Опрос проводился анонимно интервьюерами на основе формализованного интервью. Все женщины на момент проведения опроса были совершеннолетними. Более подробно методы исследования и характеристика выборки представлены в предыдущих публикациях (Русакова 2012; Odinokova et al. 2014).

Возраст вовлечения в проституцию оценивался с помощью вопроса «Укажите, пожалуйста, свой возраст на момент вашего первого коммерческого сексуального контакта с мужчиной (в обмен на деньги, ценности, наркотики или что-то иное)». В этой статье в анализ включены респонденты, указавшие возраст первого вступления в половую связь за вознаграждение (73\%; N = 654). Для дальнейшего анализа выборка была разделена на две сравнительные группы: респонденты, у которых первый оплаченный сексуальный контакт состоялся в возрасте до 18 лет, и респонденты, у которых он состоялся в возрасте 18 лет и старше.

Пути вовлечения несовершеннолетних в проституцию детально описаны в зарубежных исследованиях: показано, что важными факторами являются сексуальное и физическое насилие, пренебрежение в родительской семье, побег из дома, ранний возраст начала половой жизни, норма- 
лизация коммерческого секса в ближайшем социальном окружении, зависимость от алкоголя или наркотиков (Wilson, Widom 2010; Reid 2011; Oak Foundation 2016). Эти обстоятельства раннего вовлечения в проституцию положены в основу нашего сравнительного анализа. В статистическом анализе проверялись следующие группы факторов (табл. 1): условия воспитания в родительской семье, употребление алкоголя и наркотиков, характеристики отношения к проституции респондентов и их сверстников, характеристики сексуального опыта респондентов, включая опыт пережитого сексуального насилия. Оценка связи указанных факторов с ранним вовлечением в проституцию осуществлялась в таблицах сопряженности с помощью критерия $\chi^{2}$ Пирсона, а также с помощью бинарного логистического регрессионного анализа.

Анализ имеет ряд ограничений. Исследование построено по ретроспективному плану, данные могут подвергаться искажениям в связи с возможным действием эффектов памяти; не предусмотрена контрольная группа женщин, не вовлеченных в проституцию; выводы распространяются только на тех вовлеченных в проституцию в несовершеннолетнем возрасте женщин, которые продолжили занятие проституцией во взрослом возрасте; из анализа исключены женщины, которые не смогли вспомнить точный возраст начала занятия проституцией; в выборку не вошли женщины, которые жестко контролируются организаторами (исключен доступ исследователей).

\section{Результаты}

Каждая десятая женщина (10,7\%) начала заниматься проституцией в возрасте до 18 лет. В большинстве случаев дебют приходился на возраст $20-25$ лет (53\%) или старше (17,1\%). Каждая пятая опрошенная впервые вступила в сексуальный контакт за деньги в 18-19 лет. Рассмотрим разные указанные выше гипотетические факторы раннего вовлечения в проституцию отдельно.

Условия семейного воспитания женщин, вовлеченных в проституцию в возрасте до 18 лет, могут быть охарактеризованы как менее благополучные (табл. 1). Женщины, вовлеченные в проституцию до 18 лет, статистически значимо чаще воспитывались в малообеспеченных семьях, семьях с одним родителем или с отчимом/мачехой, чаще характеризуют отношения в семье как холодные или конфликтные, чаще сообщают о более низком образовании матери. Также они статистически значимо чаще воспитывались в семьях, где имели место супружеские измены со стороны обоих родителей. Практика физических наказаний связана с более ранним вовлечением в проституцию, тогда как распространенность словесных наказаний в унижающей или оскорбительной форме в обеих группах значимо не различалась. 
Характеристики опыта женщин

в зависимости от возраста вовлечения в проституцию

\begin{tabular}{|c|c|c|c|c|c|}
\hline & 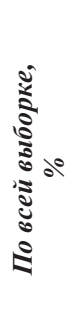 & 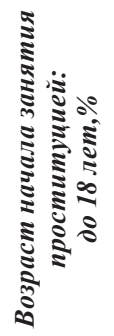 & 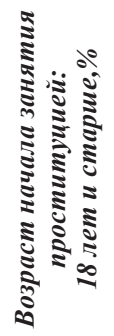 & 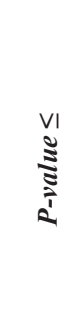 & 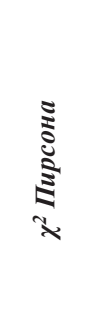 \\
\hline \multicolumn{6}{|l|}{ УСЛОВИЯ ВОСПИТАНИЯ } \\
\hline Полная семья, оба родных родителя & 62.7 & 38.6 & 65.6 & 0.001 & 19.498 \\
\hline \multicolumn{6}{|l|}{ ОБРАЗОВАНИЕ РОДИТЕЛЕЙ } \\
\hline $\begin{array}{l}\text { Высшее образование } \\
\text { у отца (отчима) }\end{array}$ & 32.1 & 19.6 & 33.4 & $\mathrm{H} / 3$ & 3.673 \\
\hline $\begin{array}{l}\text { Высшее образование } \\
\text { у матери (мачехи) }\end{array}$ & 31.3 & 19.7 & 32.6 & 0.05 & 4.243 \\
\hline \multicolumn{6}{|c|}{ ПРЕОБЛАДАВШИЙ ХАРАКТЕР ВЗАИМООТНОШЕНИЙ В СЕМЬЕ } \\
\hline Холодные, конфликтные, враждебные & 8.8 & 31.3 & 6.1 & 0.001 & 47.609 \\
\hline \multicolumn{6}{|c|}{ САМООЦЕНКА МАТЕРИАЛЬНОГО БЛАГОПОЛУЧИЯ В СЕМЬЕ } \\
\hline Нужда, бедность & 25.4 & 42.6 & 23.3 & 0.001 & 12.028 \\
\hline \multicolumn{6}{|c|}{ НОРМЫ И ЦЕННОСТИ В РОДИТЕЛЬСКОЙ СЕМЬЕ } \\
\hline $\begin{array}{l}\text { Супружеские измены } \\
\text { со стороны отца (отчима) }\end{array}$ & 19.9 & 43.8 & 17.4 & 0.001 & 18.915 \\
\hline $\begin{array}{l}\text { Супружеские измены } \\
\text { со стороны матери (мачехи) }\end{array}$ & 6.1 & 17.5 & 4.8 & 0.001 & 14.529 \\
\hline $\begin{array}{l}\text { Снисходительное или безразличное } \\
\text { отношение к супружеским изменам } \\
\text { со стороны матери (мачехи) }\end{array}$ & 58.5 & 61.3 & 58.1 & $\mathrm{H} / 3$ & 0.633 \\
\hline
\end{tabular}

Продолжение таблицы на стр. 272 


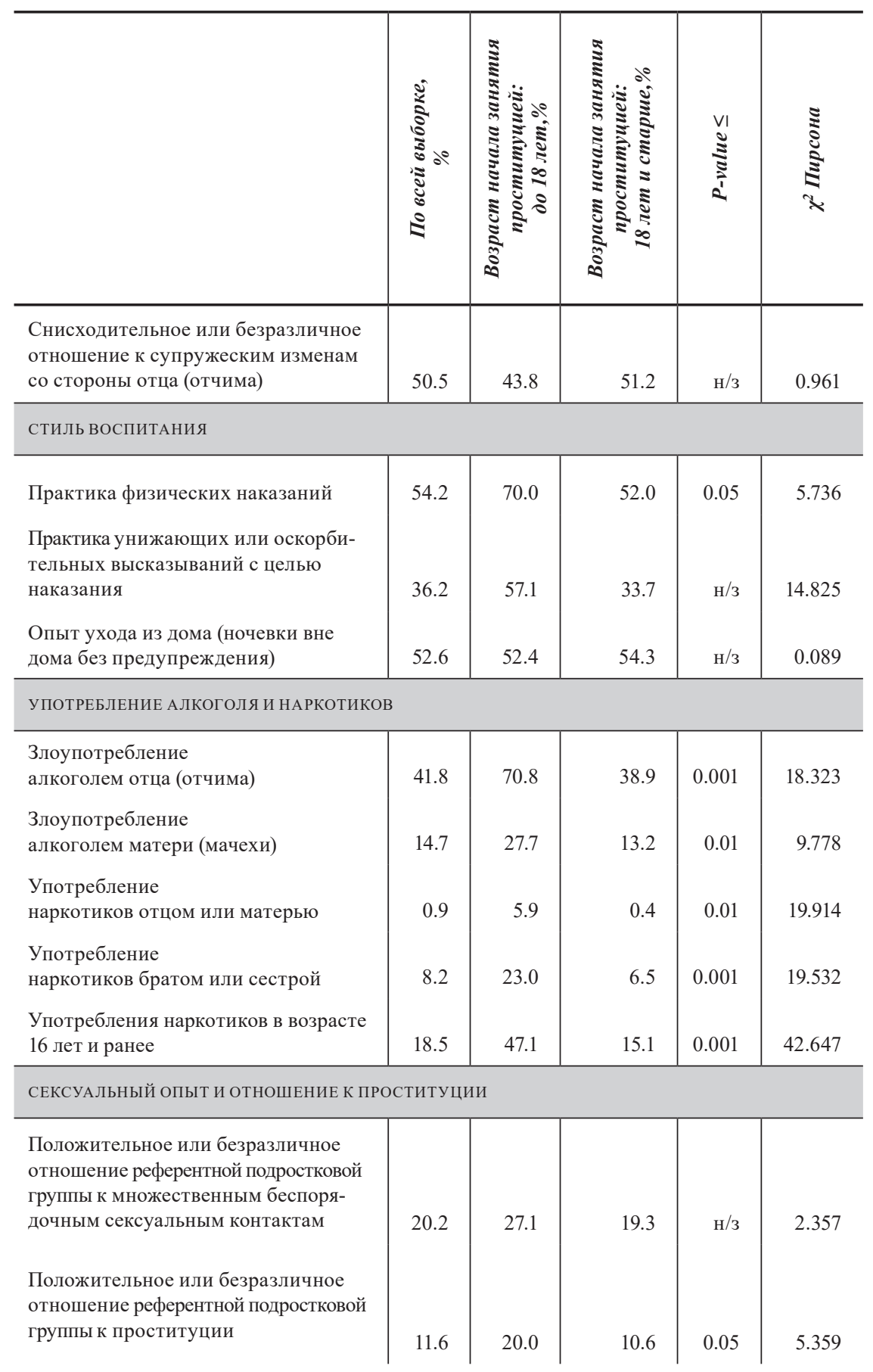




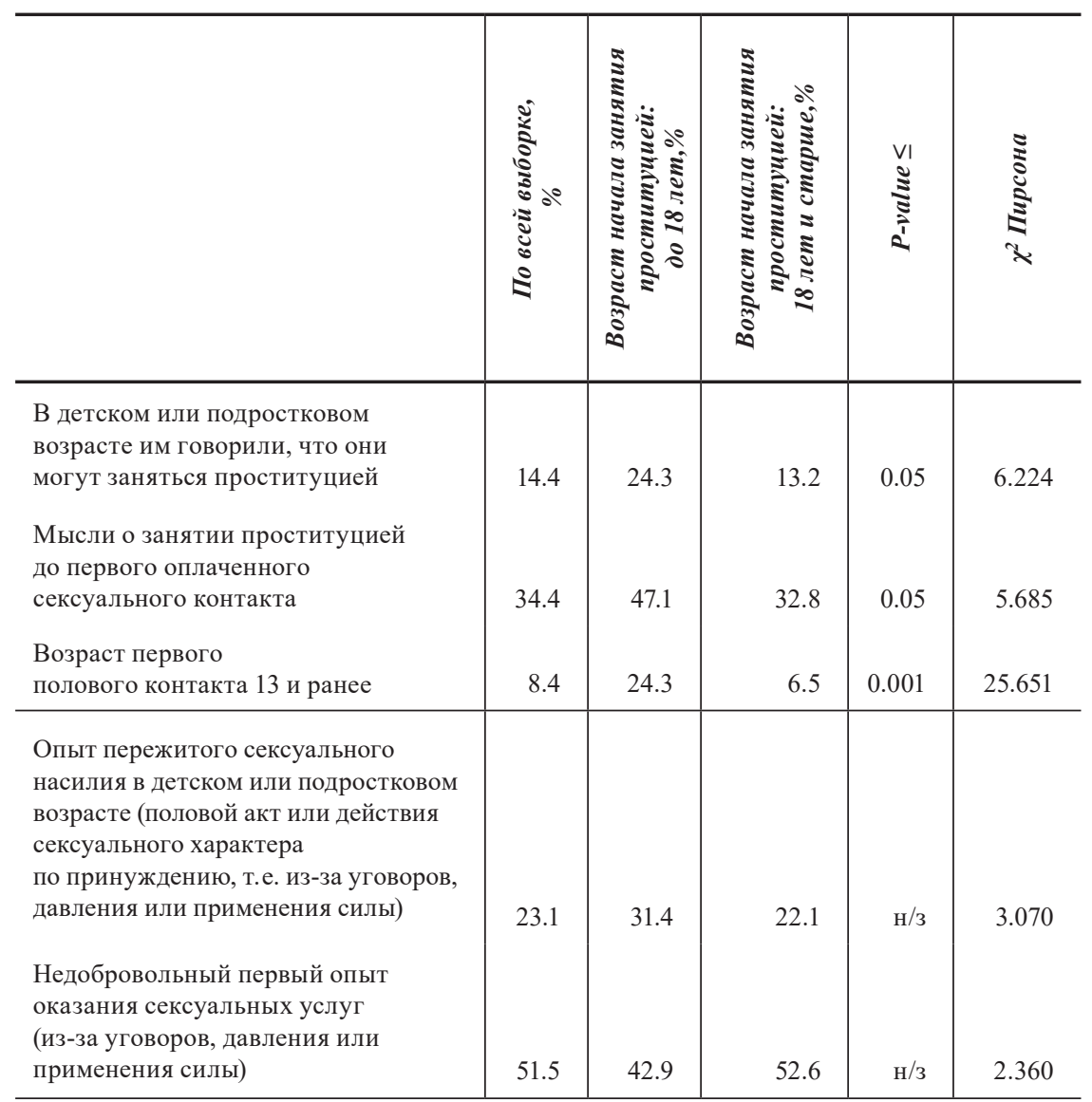

Побег из дома, которому могут предшествовать холодные или конфликтные отношения с родителями и насилие в семье, рассматривается как один из основных путей вовлечения в проституцию у несовершеннолетних (Wilson, Widom 2010; Reid 2011). Жизнь на улице создает для девушек повышенные риски вовлечения в проституцию, поскольку они нуждаются в деньгах для выживания и практически немедленно попадают в поле зрения организаторов проституции. В нашем исследовании половина женщин, занимающихся проституцией, имели опыт ухода из родительского дома, однако распространенность этого опыта не различалась в зависимости от возраста начала занятия проституцией. Возраст вовлечения в проституцию был значимо связан со всеми изучавшимися показателями употребления психоактивных веществ - как собственного, так и членов семьи.

Женщины, которые начали заниматься проституцией в возрасте до 18 лет, статистически значимо чаще сообщают о том, что их референтная группа 
сверстников относилась к проституции положительно или безразлично, что кто-либо говорил им в детстве о том, что они могут стать проститутками, а также что они сами рассматривали для себя такую возможность.

Распространенность пережитого сексуального насилия среди обеих исследуемых групп женщин значимо не различалась: каждая четвертая в выборке сталкивалась в детстве с какой-либо формой сексуального насилия. Оценка своего первого опыта оказания сексуальных услуг как недобровольного (из-за уговоров, давления или применения силы) также не связана с возрастом начала занятия проституцией. Каждый второй эпизод начала оказания сексуальных услуг произошел по принуждению.

\section{Значимые факторы начала занятия проституцией в возрасте до 18 лет}

Для оценки значимых факторов начала занятия проституцией в возрасте до 18 лет была построена модель бинарного логистического регрессионного анализа (табл. 2). При выборе модели логистической регрессии в качестве возможных независимых переменных рассматривались переменные, продемонстрировавшие статистически значимую связь с зависимой переменной в таблицах сопряженности (14 переменных). Были исключены ковариаты возраста знакомства с наркотиками (ранняя проба алкоголя респондентом и употребление психоактивных веществ членами семьи). Кроме того, в модель были включены оценка своего первого опыта оказания сексуальных услуг как недобровольного и опыт пережитого сексуального насилия в детском или подростковом возрасте (несмотря на то, что эти переменные не были связаны с возрастом начала занятия проституцией в таблицах сопряженности), поскольку в теоретическом дискурсе идея о добровольности сексуальных отношений является основой разделения проституции несовершеннолетних и взрослых. В финальную модель регрессии при использовании пошагового метода включения (forward stepwise selection) вошли семь переменных: (1) город; (2) условия воспитания (полная семья, оба родных родителя vs. иное); (3) преобладавший характер взаимоотношений в семье (холодные, конфликтные vs. иное); (4) супружеские измены со стороны отца или отчима (были vs. не были); (5) возраст первой пробы наркотиков (13 лет и младше vs. 14 лет и старше); (6) возраст, в котором произошел первый половой акт (полных лет); и (7) вступление в сексуальные отношения по принуждению в детстве или подростковом возрасте (вступала vs. не вступала).

$R$-квадрат Наделькеркеса $(R 2$ Nadelkerkes $=0,378)$ указывает на то, что с помощью нашей модели логистической регрессии можно объяснить 37,8 \% дисперсии зависимой переменной. Наиболее значимым фактором раннего вовлечения в проституцию является ранее знакомство с наркотиками (до 14-летнего возраста): этот опыт в 38 раз повышает вероятность 
начала занятия проституцией до наступления совершеннолетия. Основным семейным фактором риска раннего вовлечения в проституцию является психологическая атмосфера в семье: холодные или конфликтные отношения в 4,6 раза повышают вероятность вовлечения в проституцию до совершеннолетия. Воспитание в полной семье с родными родителями, напротив, является сильным протективным фактором (в таких семьях эта вероятность в 3,6 раза ниже). Также риск раннего вовлечения в проституцию был в 2,8 раза выше в случае наличия в семье супружеских измен со стороны отца. Обнаруженная взаимосвязь раннего начала занятия проституцией с воспитанием в семье с холодными и конфликтными отношениями, в неполной семье, с ранней пробой наркотиков согласуется с данными зарубежных исследований (Klatt et al. 2014; Reid 2014; Clarke et al. 2012; Loza et al. 2010).

Таблица 2

Факторы начала занятия проституцией до 18 лет (регрессионный анализ)

\begin{tabular}{|c|c|c|}
\hline & AOR (95.0\% C.I.) & $\begin{array}{c}P \text {-value } \\
\leq\end{array}$ \\
\hline Город (Санкт-Петербург) & $0.254(0.132-0.489)$ & 0.001 \\
\hline Возраст первой пробы наркотиков ( $\geq 13$ лет) & $38.938(5.729-264.638)$ & 0.001 \\
\hline $\begin{array}{l}\text { Характер взаимоотношений семье } \\
\text { (холодные; конфликтные, враждебные) }\end{array}$ & $4.583(2.104-9.984)$ & 0.001 \\
\hline Полная семья, оба родных родителя & $0.274(0.147-0.513)$ & 0.001 \\
\hline $\begin{array}{l}\text { Супружеские измены } \\
\text { со стороны отца (отчима) }\end{array}$ & $2.791(1.362-5.720)$ & 0.01 \\
\hline $\begin{array}{l}\text { Возраст, в котором } \\
\text { произошел первый половой акт }\end{array}$ & $0.514(0.416-0.635)$ & 0.001 \\
\hline $\begin{array}{l}\text { Опыт пережитого сексуального насилия } \\
\text { в детском или подростковом возрасте }\end{array}$ & $0.384(0.178-0.828)$ & 0.05 \\
\hline
\end{tabular}

В полученной нами регрессионной модели каждый год снижения возраста первого полового контакта вдвое увеличивает вероятность начала занятия проституцией в несовершеннолетнем возрасте. Интервенции, направленные на предотвращение ранних половых контактов среди подростков, могут также снизить и вовлечение их в проституцию. Этот результат соответствует данным, полученным в проспективном когортном исследовании (Wilson, Widom 2010).

Несмотря на то, что детско-подростковый опыт сексуального насилия не был ассоциирован с возрастом начала предоставления сексуальных 
услуг в таблицах сопряженности, при контроле других факторов он вошел в модель со статистически значимым коэффициентом. Вступление в сексуальные отношения по принуждению в детстве или подростковом возрасте во множественной логистической регрессии было негативно связано с ранним вовлечением в проституцию, таким образом, начало занятия проституцией в возрасте до 18 лет связано с оценкой своего раннего полового опыта как добровольного. В зарубежных исследованиях было показано, что раннее вовлечение в проституцию либо не было связано с пережитым в детстве сексуальным насилием (Clarke 2012), либо было связано с ним положительно (Reid 2014). В нашем исследовании были получены противоположные результаты. Это может объясняться тем, что женщины, начавшие заниматься проституцией в старшем возрасте, обладают более адекватными представлениями о том, что следует считать сексуальным насилием в детстве, а женщины с неблагоприятными условиями семейного воспитания склонны оценивать свой сексуальный опыт как добровольный в силу нормализации принуждения. Лонгитюдная методология, использовавшаяся в зарубежных исследованиях, позволила бы исключить влияние интерпретации самими респондентами фактов их детской жизни.

\section{Выводы и заключение}

Исследование продемонстрировало, что каждая десятая женщина начала заниматься проституцией в возрасте до 18 лет. Такие женщины чаще воспитывались в неблагоприятных условиях, включающих холодные, конфликтные и враждебные отношения в родительской семье, ранний сексуальный дебют, раннюю пробу наркотиков и нормализацию супружеских измен. Оценка своего первого оплаченного сексуального контакта как добровольного не была связана с возрастом начала занятия проституцией. Таким образом, результаты исследования показывают, что женщин в проституцию приводят различные обстоятельства. Одно из самых важных - это условия воспитания.

Женщины, занимающиеся проституцией,- это крайне неоднородная социальная группа. В ней можно обнаружить женщин, которые рассматривают занятие проституцией как трудовую занятость, тех, кто нуждается в защите от насилия и заинтересован в декриминализации проституции, и тех, кто был вовлечен в проституцию в несовершеннолетнем возрасте или через насилие и не в силах сменить деятельность без специальной помощи. Жесткая теоретическая позиция, основанная на обобщении всех женщин, занимающихся проституцией, как жертв, «девиантов» или работниц, неминуемо игнорирует потребности и интересы части из них. В современной российской социальной политике и праве проституция рассматривается как девиация, которая влечет за собой административную ответственность. 
Общественно-политические дискуссии о мерах «контроля проституции» включают в себя обсуждение как легализации, так и ужесточения наказаний. Однако вопросы профилактики вовлечения, а также помощи на этапе «выхода» из проституции незаслуженно исключены из этой дискуссии. Жизненные траектории, приводящие в проституцию детей и взрослых, могут существенно различаться, а информация о них должна быть использована при разработке мер социальной работы в этой области.

\section{Список источников}

Гилинский Я.И. (2004) Девиантология: сочиология преступности, наркотизма, проституции, самоубийств и других «отклонений». СПб.: Юридический Центр Пресс.

Нартова Н. А., Крупец Я.Н. (2010) Переопределение границ между трудом, удовольствием и насилием: секс-работа как особый вид неформальной занятости. Журнал исследований сочиальной политики, 8 (4): 537-550.

ООН (1989) Конвенция о правах ребенка от 20.11.1989 г.

ООН (2000) Факультативный протокол к Конвенщии о правах ребенка, касающийся торговли детьми, детской проституции и детской порнографии от 25.05 .2000 г.

Русакова М. М. (2010) Трансформация понятия «проституция» в общественных науках в контексте социального контроля: история и современность. Вестник Санкт-Петербургского университета. Серия 12. Социология, (2): 40-48.

Русакова М.М. (2012) Статистическая типология женской проституции. Современные исследования социальных проблем, 9 (17). Доступно по ссылке: http://sisp.nkras.ru/e-ru/ issues/2012/9/rusakova.pdf (дата обращения: 1 декабря 2016).

Clarke R. J., Clarke E. A., Roe-Sepowitz D., Fey R. (2012) Age at Entry into Prostitution: Relationship to Drug Use, Race, Suicide, Education Level, Childhood Abuse, and Family Experiences. Journal of Human Behavior in the Social Environment, 22 (3): 270-289.

Cobbina J.E., Oselin S. S. (2011) It's not Only for the Money: An Analysis of Adolescent versus Adult Entry into Street Prostitution. Sociological Inquiry, 81 (3):310-332.

Klatt T., Cavner D., Egan V. (2014) Rationalising Predictors of Child Sexual Exploitation and Sex-Trading. Child Abuse \& Neglect, 38 (2): 252-260.

Loza O., Strathdee S. A., Lozada R., Staines H., Ojeda V.D., Martínez G. A., Segura P.M. (2010) Correlates of Early versus Later Initiation into Sex Work in Two Mexico-US Border Cities. Journal of Adolescent Health, 46 (1):37-44.

Marcus A., Riggs R., Horning A., Rivera S., Curtis R., Thompson E. (2012) Is Child to Adult as Victim is to Criminal? Sexuality Research and Social Policy, 9 (2): 153-166.

O'Connell, Davidson J. O. (2005) Children in the Global Sex Trade. Cambridge: Polity Press.

Oak Foundation (2016) Bamboo Project. Доступно по ссылке: http://www.oakfnd.org/node/1318 (дата обращения: 1 декабря 2016).

Odinokova V., Rusakova M., Urada L.A., Silverman J.G., Raj A. (2014) Police Sexual Coercion and its Association with Risky Sex Work and Substance Use Behaviors among Female Sex Workers in St. Petersburg and Orenburg, Russia. International Journal of Drug Policy, 25 (1): 96-104.

Reid J. A. (2011) An Exploratory Model of Girl's Vulnerability to Commercial Sexual Exploitation in Prostitution. Child Maltreatment, 16 (2): 146-157.

Reid J. A. (2014) Risk and Resiliency Factors Influencing Onset and Adolescence-Limited Commercial Sexual Exploitation of Disadvantaged Girls. Criminal Behaviour and Mental Health, 24 (5): $332-344$.

Wilson H.W., Widom C. S. (2010) The Role of Youth Problem Behaviors in the Path From Child Abuse and Neglect to Prostitution: A Prospective Examination. Journal of Research on Adolescence, 20 (1):210-236. 


\title{
FACTORS ASSOCIATED WITH EARLY INITIATION INTO PROSTITUTION: RESULTS OF EMPIRICAL STUDY OF ADULT FEMALE SEX WORKERS
}

\begin{abstract}
Prostitution is usually regarded as a deviation, as a job or as the sexual exploitation of women. However, the prostitution of minors is mostly referred to as only a form of sexual abuse and exploitation. The article is based on the materials of an empirical study of adult women involved in prostitution in St. Petersburg and Orenburg $(n=654)$. It analyses the social factors and circumstances of the involvement of women into prostitution among those of them who enter prostitution at the age of 18 years and older and women who enter prostitution under the age of 18. Assessing the impact of social factors and circumstances of the involvement of women into prostitution on the age of involvement in prostitution was estimated with the Pearson $\chi^{2}$ test and binary logistic regression analysis. One in ten women in the sample became engaged in prostitution before the age of 18. In half of the cases, both groups of women reported that the first exchange of money for sex was involuntary (because of persuasion, pressure, or the use of force). Beginning prostitution before the age of eighteen was associated with family disadvantage and early age of first drug use. Life trajectories that lead to the prostitution of children and adults can vary significantly. A rigid theoretical position, based on the generalization of all women engaged in prostitution, as victims, deviants or workers, inevitably ignores the needs and interests of some of them. Discussions about social policies in relation to prostitution should include the issues of prevention of involvement, as well as assistance during the 'exit' from prostitution.
\end{abstract}

Keywords: prostitution, sexual exploitation, violence, minors, sex work

DOI: 10.17323/727-0634-2019-17-2-267-280

Veronika Odinokova - PhD, senior researcher, Sociological Institute of FCTAS RAS, Saint Petersburg, Russian Federation. Email: veronika.odinokova@gmail.com

Ksenia Eritsyan - PhD, senior lecturer, National Research University Higher School of Economics, Saint Petersburg, Russian Federation. Email: ksenia.eritsyan@gmail.com

Maia Rusakova - PhD, senior researcher, Sociological Institute of FCTAS RAS, Saint Petersburg, Russian Federation. Email: maia@ngostellit.ru

Nina Usacheva - junior researcher, Sociological Institute of FCTAS RAS, Saint Petersburg, Russian Federation. Email: marudova_n.m@mail.ru 


\section{References}

Clarke R. J., Clarke E. A., Roe-Sepowitz D., Fey R. (2012) Age at Entry into Prostitution: Relationship to Drug Use, Race, Suicide, Education Level, Childhood Abuse, and Family Experiences. Journal of Human Behavior in the Social Environment, 22 (3):270-289.

Cobbina J.E., Oselin S. S. (2011) It's not Only for the Money: An Analysis of Adolescent versus Adult Entry into Street Prostitution. Sociological Inquiry, 81 (3):310-332.

Gilinskiy Ya.I. (2004) Deviantologiya: sotsiologiya prestupnosti, narkotizma, prostitutsii, samoubiystv i drugikh 'otkloneniy' [Deviantology: Sociology of Crime, Drug Addiction, Prostitution, Suicide and Other 'Deviations']. St. Petersburg: Yuridicheskii Tsentr Press.

Klatt T., Cavner D., Egan V. (2014) Rationalising Predictors of Child Sexual Exploitation and Sex-Trading. Child Abuse \& Neglect, 38 (2):252-260.

Loza O., Strathdee S. A., Lozada R., Staines H., Ojeda V.D., Martínez G. A., Segura P. M. (2010) Correlates of Early versus Later Initiation into Sex Work in Two Mexico-US Border Cities. Journal of Adolescent Health, 46 (1):37-44.

Marcus A., Riggs R., Horning A., Rivera S., Curtis R., Thompson E. (2012) Is Child to Adult as Victim is to Criminal? Sexuality research and social policy, 9 (2): 153-166.

Nartova N.A., Krupets Ya.N. (2010) Pereopredelenie granits mezhdu trudom, udovol'stviem i nasiliem: seks-rabota kak osobyy vid neformal'noy zanyatosti [Revising the Borders between Labour, Pleasure and Violence: Sex-Work as a Specific Kind of Informal Employment]. Journal of Social Policy Studies, 8 (4): 537-550.

O’Connell, Davidson J. O. (2005) Children in the Global Sex Trade. Cambridge: Polity Press.

Oak Foundation (2016) Bamboo Project. Available at: http://www.oakfnd.org/node/1318 (accessed 1 December 2016).

Odinokova V., Rusakova M., Urada L.A., Silverman J. G., Raj A. (2014) Police Sexual Coercion and its Association with Risky Sex Work and Substance Use Behaviors among Female Sex Workers in St. Petersburg and Orenburg, Russia. International Journal of Drug Policy, 25 (1): 96-104.

Reid J.A. (2011) An Exploratory Model of Girl's Vulnerability to Commercial Sexual Exploitation in Prostitution. Child Maltreatment, 16 (2): 146-157.

Reid J.A. (2014) Risk and Resiliency Factors Influencing Onset and Adolescence-Limited Commercial Sexual Exploitation of Disadvantaged Girls. Criminal Behaviour and Mental Health, 24 (5): 332-344.

Rusakova M.M. (2010) Transformatsiya ponyatiya 'prostitutsiya' v obshchestvennykh naukakh v kontekste sotsial'nogo kontrolya: istoriya i sovremennost' [Transformation of the Term 'Prostitution' in Social Sciences in the Context of Social Control: A Historical Perspective]. Vestnik Sankt-Peterburgskogo universiteta. Seriya 12. Sotsiologiya [St. Petersburg university Bulletin. Series 12. Sociology], (2): 40-48. 
Rusakova M.M. (2012) Statisticheskaya tipologiya zhenskoj prostitutsii [Statistical Typology of Female Prostitution]. Sovremennye issledovaniya sotsial'nykh problem [Contemporary Social Issues]. Available at: http://sisp.nkras.ru/e-ru/issues/2012/9/rusakova.pdf (accessed 1 December 2016).

UN (1989) Convention on the Rights of the Child of 20.11.1989.

UN (2000) Optional Protocol to the Convention on the Rights of the Child on the Sale of Children, Child Prostitution and Child Pornography of 25.05.2000.

Wilson H. W., Widom C.S. (2010) The Role of Youth Problem Behaviors in the Path from Child Abuse and Neglect to Prostitution: A Prospective Examination. Journal of Research on Adolescence, 20 (1):210-236. 